Original Contribution

\title{
MANAGEMENT OF MALIGNANT PLEURAL EFFUSION - SINGLE-PORT VATS
}

\author{
D. Valchev*, Zl. Ilinov, E. Obretenov \\ Clinic of Thoracic Surgery, Prof. Dr. St. Kirkovich AD Multispeciality Hospital for Active Treatment, \\ Stara Zagora, Bulgaria
}

\begin{abstract}
Objective: Comparative analysis with emphasis on the advantages and disadvantages of single access thoracoscopic surgery compared to conventional three port in the treatment and diagnosis of malignant pleural effusions.

Materials and Methods: Prospective results were compared in 136 patients with malignant pleural effusions operated method VATS for the period 01.01.2013 - 31.05.2016 in the Clinic of Thoracic Surgery at the University Hospital "Prof. Dr. St.Kirkovich" JSC. Stara Zagora. 70 patients were operated with single access and 66 with a conventional three port thoracoscopic surgery.

Results:

She stayed postoperative days average single VATS 5.7 days, conventional 7.4. Satisfaction of patients after inclusion in the management of hospitalization single VATS - 4.3 out of six in conventional 2.9. Level of post-operative pain in the incision: Single access 1 st day 1.8 , 2nd day 0.9 , the third day 0.2 after 3rd day 0.1 Conventional access - 1st day 6.4, second day 5.0, the third day 4.0, after the third day 1.0. Operative time: Conventional access - 39 minutes, Single access -20 minutes.

Conclusion: VATS single access contributes to a greater degree to reduce the negative impacts on and without worsening a performance status of patients.
\end{abstract}

Key words: VATS, single access, malignant pleural effusion

\section{INTRODUCTION}

The use of single-port VATS in the management of malignant pleural effusions is a procedure which meets to a maximum degree the modern requirements for a minimally invasive procedure in patients with advanced oncological diseases. $(1,2)$ Creating a behavioural algorithm related to the diagnosis, treatment and type of its practical implementation is of paramount importance for both the thoracic surgeon and the patient, who, having been diagnosed with a malignant pleural effusion, is entitled to respiratory comfort during the short period of remaining life. $(3,4,5)$ Due to the bad performance status of patients with advanced malignant diseases, which are being manifested with malignant pleural effusion, it is extremely important to apply most patient-friendly minimally invasive techniques in the course of the diagnostic and treatment process. (5) Singleport VATS and the resulting

\footnotetext{
*Correspondence to: Valchev D., Clinic of

Thoracic Surgery, Prof. Dr. St. Kirkovich AD Multispeciality Hospital for Active TreatmentStara Zagora, Bulgaria; e-mail: dg_valchev@abv.bg
}

shortening of intraoperative time, reducing of operative trauma and shortening of postoperative hospital stay are essential in the management algorithm of malignant pleural effusions. $(1,6)$ Malignant pleural effusion represents a common clinical problem in patients with neoplastic diseases. In an autopsy series malignant effusions were found in $15 \%$ of the patients having died of malignant diseases. $(2,5)$ Annual incidence of malignant pleural effusion in the USA is estimated to exceed 150000 cases per year. $(7,8)$ In Germany annual incidence of malignant pleural effusions, reported in a publications in 2013, amounted to 56000 people, while in Europe the number of cases ranges between 375000 and 400000 per year. (5) Malignant pleural effusion is also one of the main reasons for exudative effusion; studies showed that $42 \%$ out of $77 \%$ exudative effusions were secondary malignant diseases. Almost all malignant tumours have been reported to be the reason for the development of malignant pleural effusions. Lung cancer is reported to be the most frequent reason, constituting approximately $40 \%$ of all malignant effusions. $(5,9,10,11)$ Breast cancer is the second most frequent reason, constituting approximately $25 \%$ of all pleural 
effusions. (5, 9, 12) Lymphoma, including Hodgin's disease, and non-Hodgin Lymphoma, are also an important reason for malignant pleural effusions. (11, 13, 14, 15) Ovarian and stomach and colon cancer are also a frequent reason. A primary tumour has not been identified in 5 to $10 \%$ of malignant effusions. $(5,11)$ Mesothelioma's frequency varies according to the geographical location.

Post mortem studies suggest that most pleural metastases arise from tumour embolism of the visceral tumour surface with secondary seeding to the parietal pleura. $(9,16)$ Other possible mechanisms include direct tumour invasion (in lung cancer, chest wall tumours and breast cancer), hematogenous spread and development of lymphogenic metastases along the parietal pleura. Malignant tumours may cause, both directly and indirectly, pleural effusions. The influence over the integrity and rheology of pleural lymphatic system, the affected parietal and mediastinal lymphatic vessels and nodes may lead to pleural fluid formation. $(5,7,9)$ Direct development of pleural tumour may also cause pleural effusion. Not all pleural effusions, detected in cancer patients prove to be malignant effusions. Patients with malignant diseases are prone to complications like congestive heart failure, pneumonia, pulmonary embolism, malnutrition, low serum albumin level, each of which may cause a symptomatic effusion, the clinical management of which differs significantly from that of a malignant effusion. That is why cytological assessment is extremely important. Cytological examination of pleural fluid requires a minimum number of samples of $250 \mathrm{ml}$. The morphology of cells in the pleural space may be hard to assess due to advanced autolitic processes and the presence of mesothelial and macrophage abnormalities. The accuracy of pleural fluid cytological evaluation is approximately $65 \%$ with specificity ratio of $97 \%$. The term "paramalignant effusion" is predominantly used for effusions which are not a direct result of pleural neoplasm, bur are related to the primary tumour. (8) Causes are reported to be postobstructive pneumonia with subsequent parapneumonic effusion; thoracic duct /ductus thoracicus/ obstruction with chylothorax development; pulmonary embolism;

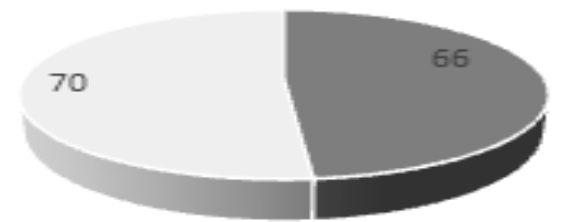

Figure 1. Total number of patients 136,70 patients underwent a single-port VATS, 66 conventional three-port VATS.

204 transudative pleural effusions as a result of postobstructive atelectasis and/or decreased plasma oncotic pressure in cancer cachexia. (8) Treatment of the primary tumour may lead to pleural effusions. The main reasons in that category include radiation therapy and administration of medications like Methotrexate, Procarbazine, Cyclophosphamide and Bleomycin. Finally, the pleural effusion may be caused by a concomitant nonmalignant disease like congestive heart failure in patients suffering from a malignant disease. The most frequent symptoms associated with a malignant pleural effusion include dyspnea and chest pain. (17) Approximately $20 \%$ of the patients may experience weight loss and fatigue. $(5,7)$ Chest X-ray examination is the instrumental method most frequently used whenever a malignant pleural effusion is suspected. Accumulation of $175 \mathrm{ml}$ pleural fluid will cause a perceptible shadow at the costo-diaphragmal angle during an X-ray exam of the chest. Computed tomography scan of the chest is a more sensitive and precise exam as compared to roentgenography and is often used for assessment of pleural effusions, because in some cases as much as $50 \mathrm{ml}$ of pleural fluid may be hidden behind the dome of the diaphragm. (8)

\section{MATERIALS AND METHODS}

For the period 01.01.2013 - 31.05.2016 136 patients were operated on due to malignant pleural effusions. 70 patients underwent a single-port VATS procedure - single port access, endobronchial intubation, talc poudrage, pleural drainage and vacuum aspiration for reducing the secretion to a minimum degree. 66 patients, included in the same study, underwent a conventional threeport VATS procedure - a three-port access, endobronchial intubation, talc poudrage, pleural drainage and vacuum aspiration for reducing the secretion to a minimum degree. (Figure 1) For starters compared hospitalization average postoperative stay, intraoperative time, degree of postoperative wound pain and patient satisfaction. 62 of the patients were women and 74 were men. (Figure 2)

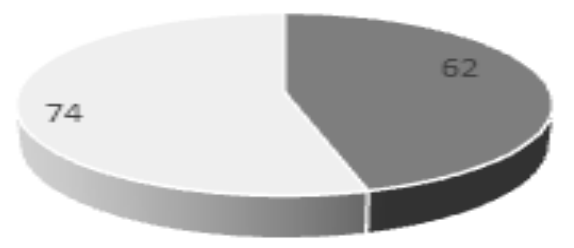

Figure 2. Total number of patients 136, 74 Men and 62 Women 
VALCHEV D., et al.

Malignant pleural effusions are more frequently observed in men probably because of the higher incidence of advanced lung cancer. Distribution of malignant pleural effusions according to histological verification and primary focus for women and for men is presented in Figure 3 and Figure 4.

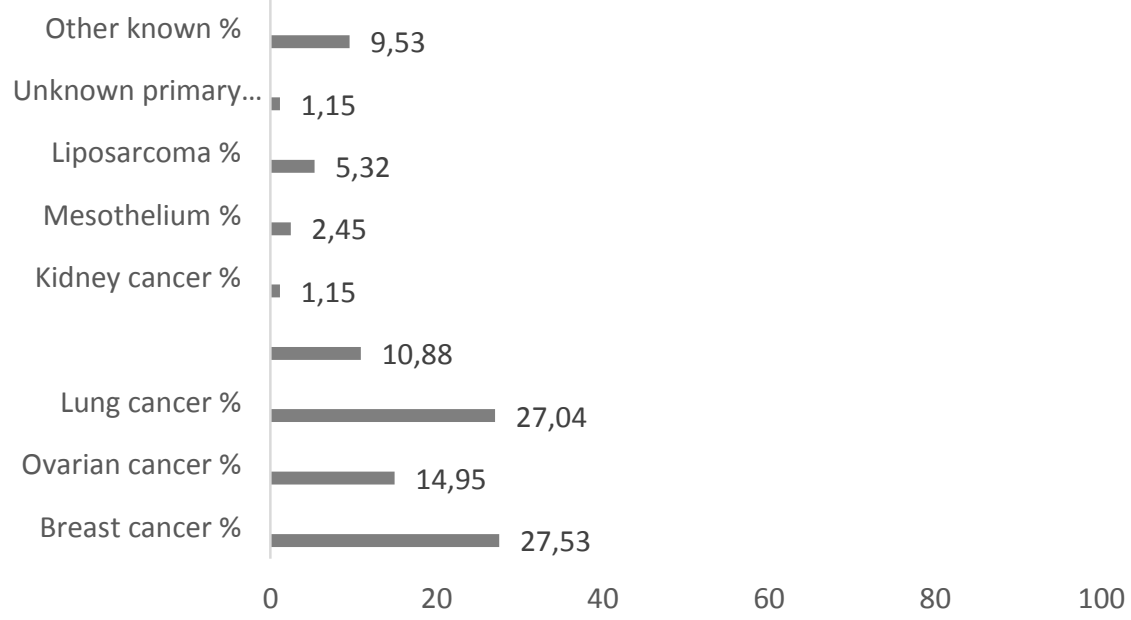

Figure 3. Women - breast cancer $27.53 \%$, ovarian cancer $14.95 \%$, lung cancer $27.04 \%$, gastrointestinal tract cancer $10.88 \%$, kidney cancer $1.15 \%$, mesothelium $2.45 \%$, liposarcoma $5.32 \%$, Carcinoma of unknown primary origin $1.15 \%$, others /unknown/ $9.53 \%$

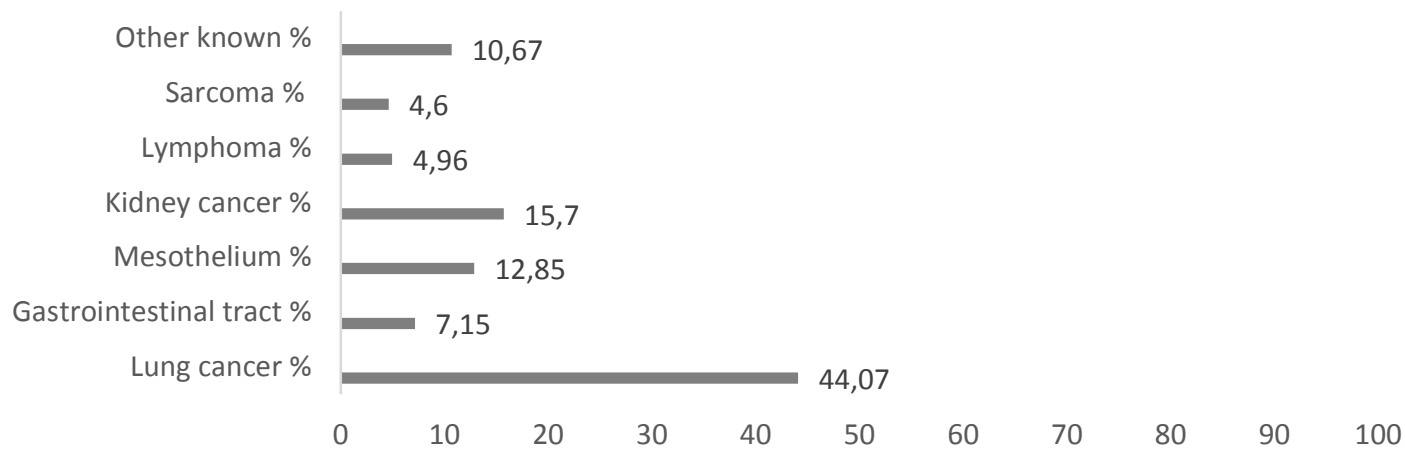

Figure 4. Men - lung cancer $44.07 \%$, gastrointestinal tract cancer $7.15 \%$, mesothelium $12.85 \%$, kidney cancer $15.70 \%$, lymphoma $4.96 \%$, sarcoma $4.60 \%$, others /carcinoma of unknown origin, thyroid gland, Ewing sarcoma, etc./ 10.67\%

Distribution of lung cancer, causing malignant pleural effusion, according to pathomorphological type for women and for men is presented in Figure 5.

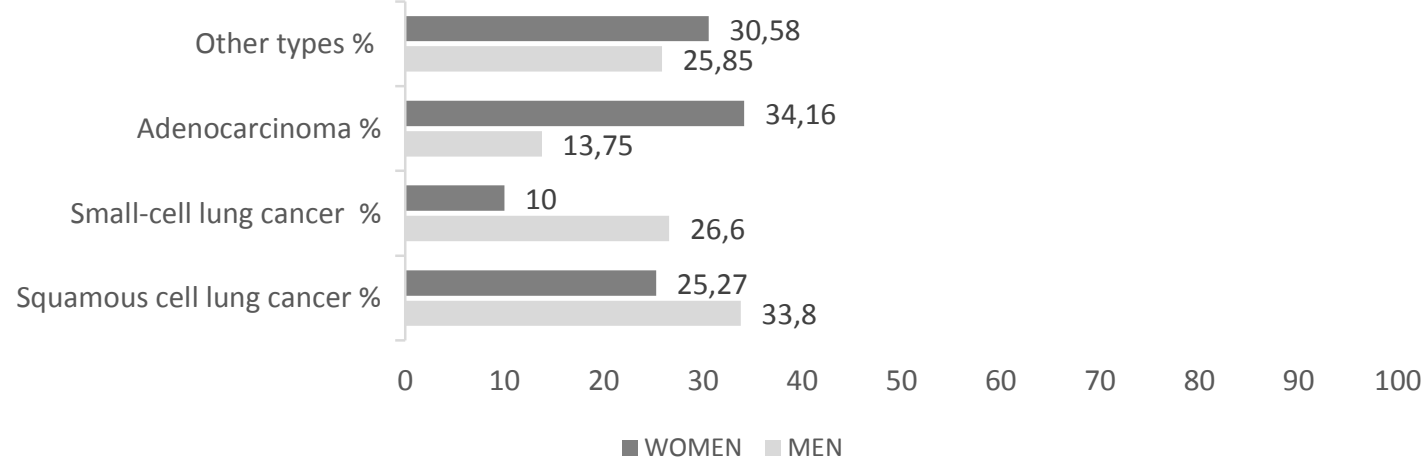

Figure 5. Pulmonary carcinoma distribution: Women - squamous cell lung cancer $25.27 \%$, small-cell lung cancer $10 \%$, adenocarcinoma $34.16 \%$, others $30.58 \%$. Men - squamous cell lung cancer $33.80 \%$, small-cell lung cancer $26.60 \%$, adenocarcinoma $13.75 \%$, others $-25.85 \%$ 
Women were aged between 28 and 80 years of age.Men were in the age range of 34-80. It is worth noting that in our study women's age was 6 years shorter as compared to that of men which can probably be explained with the higher incidence of breast cancer in young women. Average quantity of evacuated pleural fluid - $1450 \mathrm{ml} /$ range of 100-4000 ml/. Positive cytology was confirmed and histologically established in $38.90 \%$ of all malignant pleural effusions, the percentage being lower than that quoted in most reports which amounts to $65 \%$ of all samples. In our case the lower percent is probably due to the longer storage of the pleural fluid before the cytological evaluation. The standard requires for the cytological assessment to be performed not later than the second hour after sampling. The second reason for the discrepancy is the smaller quantity of pleural fluid that is subject to cytological evaluation - in most scientific reports the sample's optimal quantity is $250 \mathrm{ml}$.

\section{Surgical Technique}

The patient is positioned on the surgical table in the lateral decubitus position with a roll placed beneath the scapula to open up the intercostal spaces. Endobronchial intubation with one-lung ventilation is performed.

Single-port VATS for malignant pleural effusions involves creating a small incision of about $2.5 \mathrm{~cm}$ at the 5, 6 intercostal space, mid axillary line. An 11-mm trocar is introduced in the thoracostomy wound and is used as an entrance for the video camera; another 5-mm trocar is used as a port for additional instruments: biopsy forceps, vacuum aspirator, dissector. If necessary the said instruments are replaced with one another during the surgery.

At the end of the surgery a No18 chest catheter is placed in the thoracostomy wound with the aim of decreasing secretion to the minimum and is later removed (Photos 1-5).

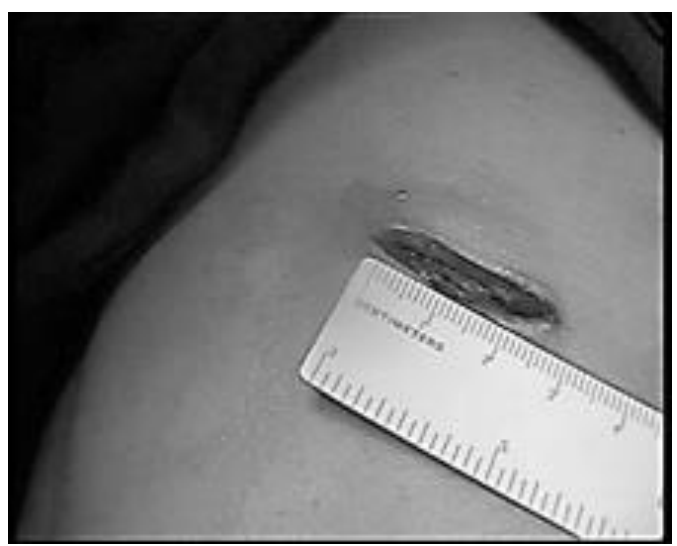

Photo1. Length and appearance of the thoracic pleural port at the 5, 6 intercostals space, anterior,mid- axillary line.

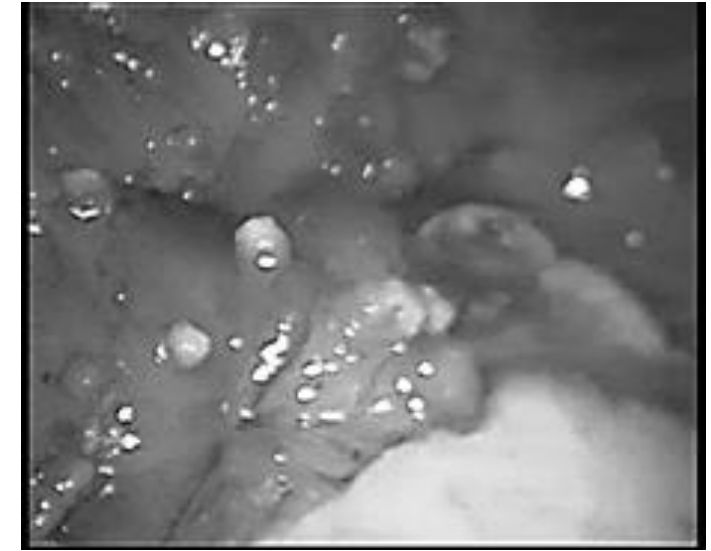

Photo 2. Pleural carcinomatosis during video-assisted thoracoscopic surgery.

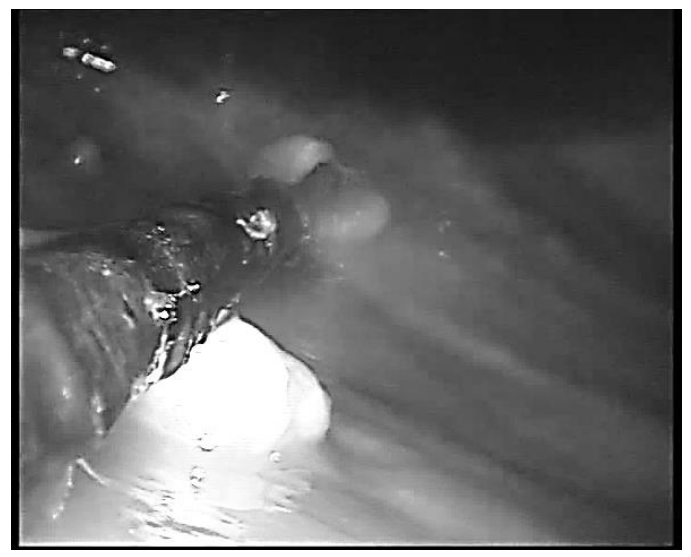

Photo 3. Pleural biopsy performed.

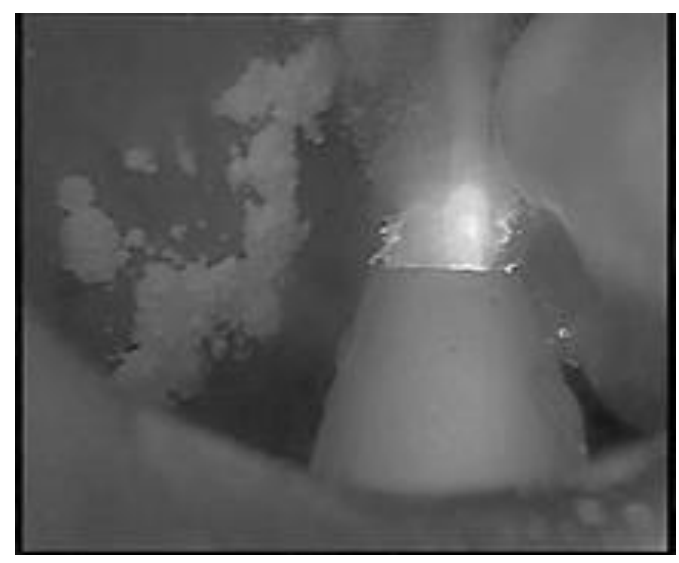

Photo 4. Talc poudrage procedure.

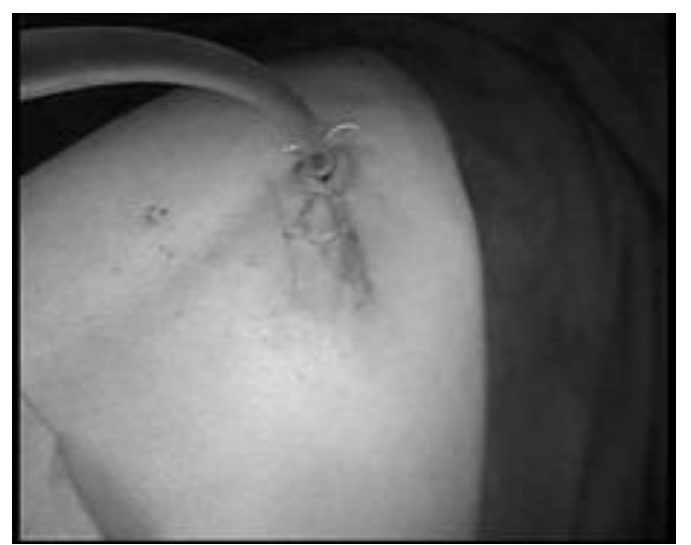

Photo 5. Draining and restituted surgical incision. 


\section{RESULTS}

Postoperative hospital stay is shown in Figure 6.

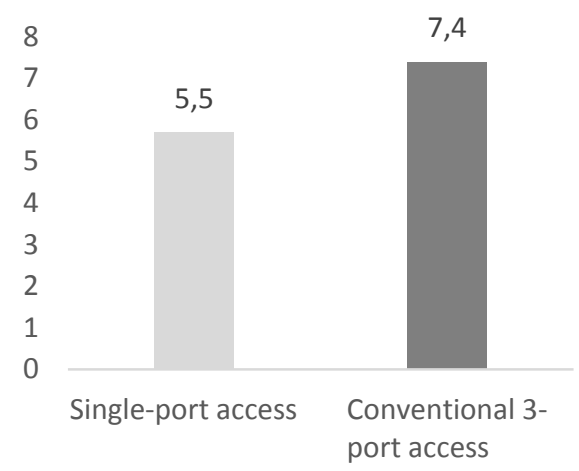

Figure 6. Patients operated on with a single-port VATS procedure - average postoperative stay: 5.5 days; Postoperative hospital stay - patients operated on with a conventional three-port VATS procedure - average postoperative stay: 7.4 days. Postoperative hospital stay is shorter by 1.45 times for single-port VATS.

\section{Patient satisfaction:}

Patients' satisfaction after the use of single-port VATS in the management of hospital period 4.2 according to a 6-point grading system; Patents' satisfaction after the use of conventional three-port VATS in the management of hospital period -2.9 according to a 6-point grading system. Patients' satisfaction after the use of single-port VATS is 1.4 times greater than with conventional threeport VATS. Patient satisfaction with the treatment is shown in Figure 7.

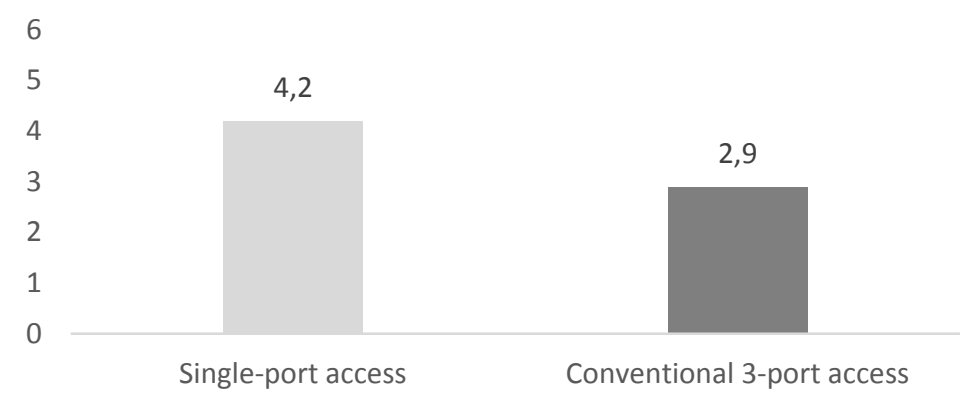

Figure 7. Patients' satisfaction according to a 6-point grading system

Postoperative pain level in the incision area assessed on the basis of a Verbal Analog Ten-point Scale: Single-port access $-1^{\text {st }}$ day: $1.8 ; 2^{\text {nd }}$ day: $0.90 ; 3^{\text {rd }}$ day: 0.20 ; after the $3^{\text {rd }}$ day: 0.1 ; Conventional access $-1^{\text {st }}$ day: $6.4 ; 2^{\text {nd }}$ day: $5.0 ; 3^{\text {rd }}$ day: $2.0 ;$ after the $3^{\text {rd }}$ day: 1.0 . Postoperative pain level in the incision area is 4.8 times lower in the Single-port access than the Conventional access. This is shown in Figure 8.

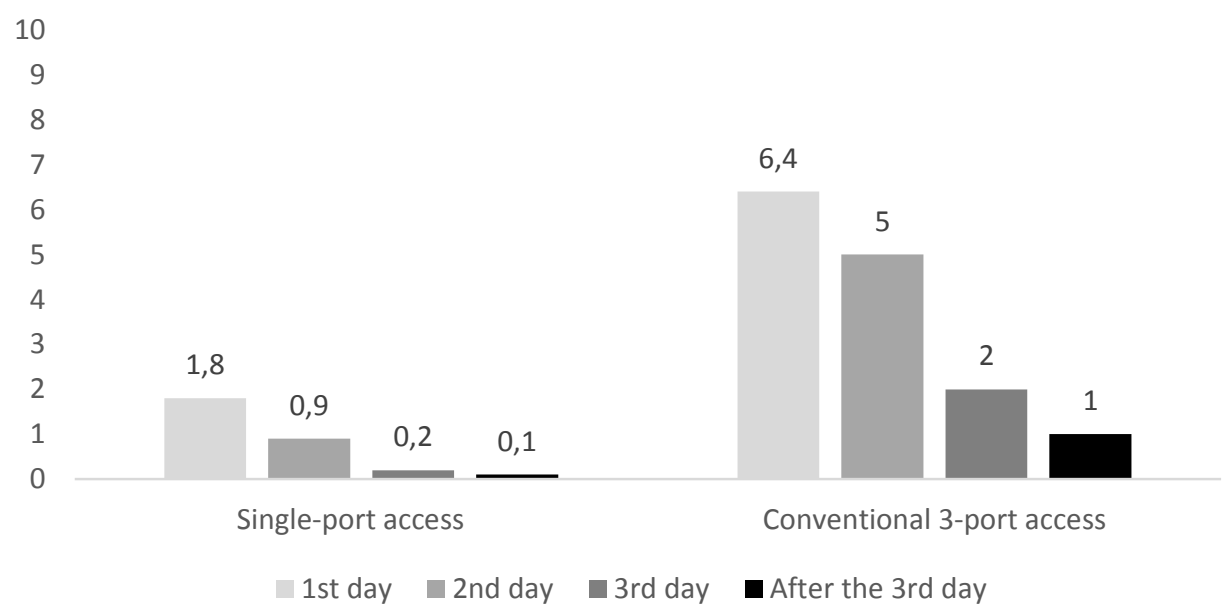

Figure 8. Postoperative pain level according to a Verbal Analog Scale. 
Certain tenderness at the port place persists for the whole period of the pleural drainage because the drainage is performed through the thoracic port. Moreover, the tenderness depends on the size of the pleural catheter as well.
Operative time: Single-port access: 20 minutes; Conventional access: 39 minutes. Operating time is shortened 1.95 times in favor of Single-port access. This is shown in Figure 9.

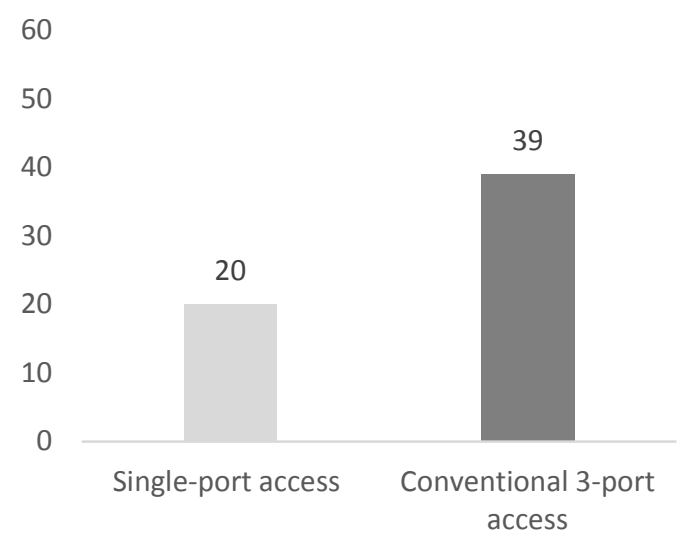

Figure 9. Operative time in minutes

In our study we had a case of an implantation metastasis from adenocarcinoma in the chest wall in the 6th postoperative month, which was successfully excised.

According to our data the 2-day shorter postoperative period after the use of single-port VATS results in lower financial costs, prompt dehospitalization of patients with malignant pleural effusion and faster return, sparing their psycho-emotional state, to their usual home environment.

\section{DISCUSSION}

The use of single-port VATS in suspected malignant pleural effusion as a part of the MPE management, has been a world tendency for the last few years. It aims at reducing to the minimum the consequences and possible complications during conventional VATS. (1, 6) Bleeding, implantation metastases at the port's location, postoperative pain with intercostal neuralgia, postoperative empyema, etc. Longer postoperative stay observed in our study, as compared to other publications, can be explained with the fact that we waited for the 24-pleural secretion to be reduced to under 50 $\mathrm{ml}$, which means that it's possible to shorten the patents' hospital stay should the fluid discharge be reduced to under $200 \mathrm{ml}$ within 24 hours.

The main difficulty, when applying the singleport VATS procedure, is the need for the surgeon to adapt to the method, as the main thoracoscopic principles of triangulation are not present. Surgical instruments and thoracoscope are introduced through a single incision on the same axis, or on separate but crossing axes, which, in certain situations, may make the work more difficult.

However, whenever a malignant pleural effusion as a result of advanced oncological disease is suspected and there are certain restrictions as to the application of surgical resection, minimally invasive procedures that could shorten the operative time and the postoperative stay are totally justified for patients with highly worsened performance status and short remaining life period. $(1,5,7)$

\section{CONCLUSION}

Higher satisfaction associated with less operativ trauma significantly lower degree of postoperative wound pain and shortened hospital stay of patients with malignant pleural effusion after VATS single access contributes to a greater degree to reduce the negative impacts on and without worsening a performance status of patients.

\section{REFERENCES}

1. Alar T, Ozcelik C.; Single-incision thoracoscopic surgery of pleural effusions for diagnosis and treatment.; Surg Endosc. Nov;27(11):4333-6, 2013.

2. Gaetano Rocco, Nicola Martucci, Carmine La Manna, David R. Jones, Giuseppe De Luca, Antonello La Rocca, Arturo Cuomo, and Rosanna Accardo ; Ten-Year Experience on 644 Patients Undergoing Single-Port (Uniportal) Video-Assisted Thoracoscopic Surgery (Ann Thorac Surg;96:434-8), 2013.

3. Danail Petrov, Georgi Kalaydzhiev, Treatment of Malignant Pleural Effusion - 
My Surgery.bg, March 2014, 14:57, Prof. Danail Petrov

4. Dimitar Kalev,; Behaviour in case of malignant pleural effusion, 02 September 2011 - My Surgery.bg

5. Michael Ried and Hans-Stefan Hofmann; The Treatment of Pleural Carcinosis With Malignant Pleural Effusion Deutsch Arztebl Int. May; 110(18): 313-318, 2013.

6. Yamada, S., Kosaka, A., Masuda, M. et al.; Minimally invasive lung and pleural biopsies using 2-mm and standard thoracoscopic equipment; Jpn $J$ Thorac Caridovasc Surg 48:11: 700-702, 2000.

7. V.B. Antony, R. Loddenkemper, P. Astoul, C. Boutin, P. Goldstraw, J. Hott, F. Rodriguez Panadero, S.A. Sahn.; Management of malignant pleural effusions. European Respiratory Journal 18: 402-419; 2001.

8. Ferreiro L, Suárez-Antelo J, Valdés L.; Pleural procedures in the management of malignant effusions.; Ann Thorac MedJanMar; 12(1):3-10, 2017.

9. A.M.Abumossalama, T.T. Abdelgawada, A.M. Sheblb; Malignant pleural effusion: Relationship between thoracoscopic findings and type of malignancy; Egyptian Journal of Chest Diseases and Tuberculosis Volume 64, Issue 2, April, Pages 399-404, 2015.

10.Takahiro Ebata, Yusuke Okuma, Yoshiro Nakahara, Makiko Yomota, Yusuke Takagi, Yukio Hosomi, Eichi Asami, Yasushi Omuro, Tsunekazu Hishima, Tatsuru Okamura, and Yuichi Takiguchi; Retrospective analysis of unknown primary cancers with malignant pleural effusion at initial diagnosis. Thorac Cancer. Jan; 7(1): 39-432016.

11.Cakir E, Demirag F, Aydin M, Erdogan Y.; A review of uncommon cytopathologic diagnoses of pleural effusions from a chest diseases center in Turkey.; CytoJournal;8:13, 2011.

12.T. Hirata, K. Yonemori, A. Hirakawa, C. Shimizu, K. Tamura, M. Ando, N. Katsumata, M. Tanimoto, Y. Fujiwara; Efficacy of pleurodesis for malignant pleural effusions in breast cancer patients. European Respiratory Journal 38: 1425-1430; 2011.

13. Mark S Williams, Edmund Cheesman, Musa Kaleem, Robert Wynn; Primary pleural precursor B-Cell lymphoblastic lymphoma; Clin Case Rep. Oct; 3(10): 858-861, 2015.

14.Das DK; Serous effusions in malignant lymphomas: a review. Diagn Cytopathol. May;34(5):335-47, 2006.

15.Yajlan Ylang, Wanzhuo Xie, Keyue Hu, Jie Sun, Xiaoli Zhu, He Huang; An aggressive form of non-Hodgkin's lymphoma with pleural and abdominal chylous effusions: A case report and review of the literature Oncol Lett. Oct; 6(4): 1120-1122, 2013.

16.Daniel Morgensztern, Saiama Waqar, Janakiraman Subramanian, Kathryn Trinkaus, Ramaswamy Govindan; Prognostic Impact of Malignant Pleural Effusion at Presentation in Patients with Metastatic Non-Small-Cell Lung Cancer; Journal of Thoracic Oncology, Volume 7, Issue 10, Pages 1485-1489, 2012.

17.Loddenkemper R. Management der malignen Pleuraergüsse. Pneumologie.; 59:120-135, 2005. 